with both open and closed ended questions followed by urine sample collection which was then analysed by CVAAS technique to determine the level of mercury. Data analysis was done by using Chi-square and incase numbers were too small for Fisher's exact test was employed. Measure of association is significant where $\mathrm{p}<0.05$ Statistical analysis was done by SPSS version 21.

Results A total of 150 participants with the age between 15 and 67 (mean age $33.77(\mathrm{SD}=12.12)$ and $33.26(\mathrm{SD}=12.83)$ years old for exposed and unexposed groups respectively) were recruited and ascertained for exposure. Urinary mercury concentrations for exposed group were higher than the referent group (mean $81.18(\mathrm{SD}=46) \mathrm{mcgHg} / \mathrm{g}$-creatinine and 5.14 $(\mathrm{SD}=2.73) \mathrm{mcgHg} / \mathrm{g}$-creatinine respectively) $(\mathrm{p}<0.05)$. Symptoms such as cough, chest tightness, tremor of hands, tremor of tongue, tremor of eyelid and trouble of walking were significantly more prevalent in exposed $(\mathrm{p}<0.05)$ than non exposed.

Discussion Body burden caused by mercury affects not only miner but also the community surrounding the mining area. Exposure to even lower amount of mercury may bring about significant health effects. Therefore there is a need for stakeholders to raise the community awareness on mercury effects and its preventive measures.

\section{WHAT ARE WE DOING ABOUT CHILDREN MINING GOLD?}

David F Goldsmith*. George Washington University, Washington DC USA

\subsection{6/oemed-2018-ICOHabstracts.684}

Introduction There is concern in the Philippines, Indonesia, central Africa, and South America related to children's employment in small scale gold mines (SSGM). Ages range from 8 to 16 years, although statistics are lacking. We know children work in SSGM because they are poor; world gold prices keep them labouring. There is appeal to banning youth from mines, and creating no children in gold processing supply lines. These approaches appear to be the most ethical solutions, however this issue is more complex.

Definition of problem Evidence from Human Rights Watch indicates there are as many as 1,000,000 children in SSGM. There are risks of traumatic injury, dermatitis and diving risks in Philippines, lead poisoning in Africa, mercury $(\mathrm{Hg})$ intoxication, and $\mathrm{Hg}$ contamination of local waters. There are remediation challenges, especially where mine tailings meet aquatic settings.

Environmental health results Local governments, NGOs, health providers, and mining companies must provide funding and alternatives such as schooling, and providing jobs to replant trees. Certify that no children $<16$ are involved with gold coming to world markets. Seek nonHg solutions to separating gold, including banning local sales of liquid $\mathrm{Hg}$.

Discussion Local university medical/public health schools should sponsor studies of children who are now or were engaged in mining, examining injury rates, nervous system effects, effects of mine dusts-silica and lead, and times in water (in Philippines and Indonesia). These endeavours should also include studies of adult miners, examining the risks of silicosis/lung disease, autoimmune/kidney disease, and cancers based on industrial hygiene measures of silica and radiation. We need innovative means to remediate environmental damage from gold mining. We need leadership in occupational health, education, exposure assessment/industrial hygiene to reduce the numbers of children in SSGM.

\section{WORKPLACE HEALTH RISKS MANAGEMENT IN DEVELOPING WEST AFRICA COUNTRIES, THE ROLE OF ACADEMIC HEALTH INSTITUTIONS}

Hayford Etteh. International Fund for Agricultural Development, United Nations, Accra, Ghana

\subsection{6/oemed-2018-ICOHabstracts.685}

Introduction This paper examines the major health threats and risks to employees in Ghana and some West African countries amidst the rapidly growing mining, metals, oil and gas industries. It looks at the role of key stakeholders, particularly academic health institutions in the evidenced-based management of occupational health to improve the health, productivity and performance of the working population.

Methods The paper was developed from extensive literature review and interview of some industry leaders to understand some historical trends of employee occupational health promotion and protection indices and the current situation of occupational health and hygiene standards in the sub-region.

Results Clearly, the present West African employee (local and expatriate) are heavily burdened with diverse kinds of health threats, both from the workplace and non-work-related sources. The threats and associated risks were noted to be hugely skewed towards infectious diseases and occupational health hazards origins. That notwithstanding, non-communicable diseases challenges, like mental health, hypertension, diabetes, cancers and musculoskeletal disorders had prominent place in the workplace health hazards and risks matrix.

Discussion Academic health institutions in West Africa, despite having major roles to play in defining and managing occupational health hazards, were noted not to be actively engaged. Training of competent professionals to run workplace wellness, occupational health and hygiene programs in high-risk workplaces in developing countries, research to have evidence based problem definitions and efficient alternative solution pathways with maximum health outcome are all some of the roles falling in the domain of academic health institutions. Legislation and occupational standards development cannot be achieved without credible research evidence support - this was noted to be a huge gap in the West-Africa sub-Region.

The way forward was identified as; key stakeholders working together using a systemic and systematic approach to progressively define and address workplace health problems to improve occupational health outcome.

I am currently and IFAD medical advisor and have been in this role for the past 7 months as consultant. Prior to assuming this position, I was a UN volunteer as a medical officer providing occupational health, primary health and emergency medical services to the UN staff deployed in North Korea. This I did for 18 months with no salary, but only basic allowance to support my basic living allowance. Before moving to North Korea, I served in a similar capacity for 10 years in Ghana, DR Congo and Lebanon with basic remuneration. I am optimistic that, this provided valuable services to contribute to the identified and shared gap (by ICOH and ILO) of far less that $10 \%$ of developing countries employees receiving occupational health services consistent with workplace risks 